\title{
Maldiciones y profecías: representaciones de la destrucción socionatural de un pueblo en la prensa colombiana
}

Curses and prophecies: representations of the socionatural destruction of a town in the Colombian press

RESUMEN

Este artículo indaga por las representaciones que de la destrucción socionatural del casco urbano de Gramalote (Norte de Santander, Colombia) construyeron los diarios La Opinión (local) y El Tiempo (nacional). Es una investigación histórico-hermenéutica, de análisis documental. A partir de la codificación abierta de 48 textos periodísticos de ambos diarios, se construyeron familias categoriales permitiendo determinar cuatro representaciones del hecho: la persona ama/esclava de la naturaleza; un pueblo sin raíces; ausencia de liderazgo, por último, y causas místicas y proféticas, siendo esta representación la que registró mayores referencias. Así, los medios masivos hacen evidentes los entramados de sentidos que envuelven a las comunidades, permitiendo la comprensión de los desastres y de las historias del fin del mundo en las fronteras de lo socionatural, lo mágico y lo sagrado, desde donde es posible pensar también la gestión del riesgo.

Palabras clave: prensa, catástrofe, representaciones.
Gladys Adriana

ESPINEL RUBio

Universidad Francisco de Paula

Santander, Cúcuta, Colombia.

ロ gladysespinel@ufps.edu.co

(1) ORCID: 0000-0002-8796-9257

s Google Scholar 


\begin{abstract}
This article investigates the representations of the socionatural destruction of the urban area of Gramalote (Norte de Santander, Colombia) made by the newspapers La Opinion (local) and El Tiempo (national). This documental analysis constitutes a historical-hermeneutical investigation. Through the open coding of 48 journalistic texts from both newspapers, the research constructed families of categories producing four representations of the event: the person as a master/slave of nature; a people without roots; the absence of leadership and mystical and prophetic causes being the latter the one that registered most references. Thus, the mass media make evident the webs of meanings that surround the communities, allowing the comprehension of disasters and end-of-the-world stories at the borders of the socio-natural, the magical and the sacred, from where it is also possible to think risk management.
\end{abstract}

Keywords: press, catastrophe, representations, Gramalote (Norte de Santander, Colombia).

\title{
Introducción
}

L

as narrativas sobre el fin del mundo han persistido en la historia de las sociedades. Con cada cambio de siglo, de milenio o episodio catastrófico, que incluya la transformación de los territorios y el paisaje, emergen las paranoias por el advenimiento del apocalipsis, el acabose de la tierra o la desaparición de los humanos. Y con el cierre de la primera década del siglo XXI no hubo excepción. La mediatización de la denominada profecía maya, generó todo tipo de predicciones de lo que podría pasar a medida que se acercaba el 2012.

Sin embargo, aunque el planeta no se destruyó, el cambio climático, la deforestación y otros fenómenos antrópicos se intensificaron y empezaron a ocupar un lugar central en las preocupaciones por el futuro del planeta. Uno de esos hechos fue la destrucción del casco urbano de Gramalote (Norte de Santander), un municipio ubicado en las faldas de la cordillera de los Andes, al nororiente de Colombia, que empezó a 'desmoronarse' el 17 de diciembre del 2010. Tras 153 años de historia, el casco urbano construido por campesinos cafeteros con arraigadas creencias 
católicas y tradicionalmente, vinculados con el Partido Conservador ${ }^{1}$, sucumbió.

En el 2010, ese municipio, como toda Colombia, enfrentaba una ola invernal generada por el fenómeno de la Niña. Ni la comunidad ni la institucionalidad pública se habían preparado para lo que iba a suceder: un movimiento telúrico de $2.9^{\circ}$ en la escala de Richter $^{2}$, que a simple vista puede ser inocuo, se cruzó con la licuefacción ${ }^{3}$ del suelo debido al aumento de lluvias. Juntos provocaron el deslave del cerro de La Cruz, que movió el casco urbano.

En Colombia son varias las ciudades que han sido destruidas por fenómenos naturales en su historia reciente: Popayán por un terremoto (1983); Armero por una avalancha provocada por el deshielo del volcán Nevado del Ruíz (1985); y Armenia también por un terremoto (1999). En esas tres ciudades hubo víctimas fatales; en Gramalote ninguna, pues las autoridades desalojaron el pueblo. Esta situación despertó la solidaridad del país y de los medios de comunicación. La Opinión (local) y El Tiempo (nacional) fueron medios fundamentales a la hora de informar lo que estaba ocurriendo en el territorio y con sus habitantes.

Los estudios sobre la relación entre la prensa escrita y el medio ambiente han tomado fuerza en la última década, dado que el crecimiento de la población mundial es proporcional al impacto sobre los ecosistemas, además, porque los medios de comunicación que utilizan como criterio de noticiabilidad el impasse, tienden a darles relevancia a los fenómenos naturales siempre que estos afecten a un mayor número de personas.

Llasat-Botija et al. (2016), analizaron la evolución de las noticias y el tratamiento que se le ha dado a los riesgos naturales entre 1981 y el 2010 en el diario La Vanguardia de Cataluña, España, e identificaron los factores que influyen en la cobertura informativa y la percepción de estos eventos están relacionados con el impacto económico que tienen los riesgos naturales y están asociados a una mayor vulnerabilidad y exposición de los seres humanos. Los factores que inciden en el cubrimiento son: excepcionalidad; severidad; contexto sociopolítico o las consecuencias políticas; localización del evento (entre más cercano a zonas urbanas, donde vive

\footnotetext{
Uno de los partidos tradicionales colombianos con origen en el siglo XIX y que con el Partido Liberal se han disputado la hegemonía política en la Nación.

La medición se hace ahora en Mw (Magnitud del movimiento sísmico).

Comportamiento del suelo que estando sujeto a la acción de una fuerza externa pasa de un estado sólido a un líquido, o adquieren la consistencia de un líquido pesado.
} 
gran parte de la población, mayor cobertura); víctimas y elementos afectados, son estratégicos. Con relación al enfoque, es importante aclarar que las notas periodísticas se dedican más a explicar las consecuencias, más no el fenómeno en sí. Pese a esto, se evidencia tanto un aumento en las descripciones con infografías como de los científicos y técnicos expertos como fuentes, señalan Llasat-Botija et al. (2016).

Previamente, Carabaza (2007) determinó el papel de la prensa en la construcción de las representaciones sobre la problemática ambiental en los habitantes de Saltillo, México. El trabajo resulta ser significativo, pues, al profundizar en la relación medios-medio ambiente, describió las tendencias en investigación que existían hasta la fecha, organizándolas en tres momentos: 1. La visión que los medios tienen del medio ambiente, en la que se privilegia el análisis de contenido; 2. Los efectos de los medios en el área medioambiental en donde se analizan los mensajes y las campañas; y 3. Relacionada con los efectos de los efectos de los medios en la ideología medioambiental, a su vez, la relación con la cultura. Acá hay aproximaciones críticas a los problemas, pero no se ofrecen soluciones pragmáticas.

Para Carabaza (2007), los medios no desarrollan actitudes educativas ni críticas para informar sobre el medio ambiente, quedándose en la presentación descriptiva de los desastres naturales y la fauna, sin una perspectiva económica, política o social que explique la problemática ambiental. Una década después, Andrade et al. (2018) insisten en que la prensa mundial otorga mínima importancia a los temas medioambientales, con excepción de los casos en que los humanos son afectados por fenómenos naturales. En su trabajo, identificaron las representaciones mediadas por la prensa mexicana de estos acontecimientos, en donde la 'escabrosidad' fue el criterio más repetitivo en la forma de presentar la información analizada. En este orden, Ortiz (2015) encontró los aspectos ambientales o de cambio climático son mínimamente abordados y cuando lo hacen, es por la ocurrencia de catástrofes naturales o provocadas por el ser humano. Además, Castillo y López (2019) determinaron que los medios de comunicación son transmisores de ideas ambiguas frente a la amenaza y la vulnerabilidad, además, que el cubrimiento se hace sobre el desastre y no desde el riesgo. Al finalizar su estudio sobre los marcos de los desastres naturales en la prensa chilena, Tagle (2017) se pregunta cuánta de la información es verdaderamente útil ante la emergencia, pues insiste en que los medios podrían cumplir de mejor manera sus funciones ante este tipo de eventos. 
Pese a esto, no se debe obviar el rol significativo de los medios masivos en estas situaciones que ponen en riesgo vidas humanas, pues son canales privilegiados para que los gestores de la crisis informen al público que, en ocasiones, está en peligro inminente (Reis et al., 2013). Como se evidencia, la mayoría de las investigaciones realizadas obedecen al análisis del tratamiento periodístico de las catástrofes por cuanto tienen mayor atención de los medios de comunicación; Piñuel (2013) critica el hecho de que el periodismo ambiental se dé sólo cuando hay Cumbres ambientales o cuando suceden catástrofes en los periodos intercumbres. Al respecto, Lörcher y Neverla (2015) y Schäfer y O'Neill (2017) estudiaron los temas, subtemas y frame que sobre el cambio climático registran los medios de comunicación en línea, los medios públicos y la manera como estos dan cuenta de los reportes. Así que otro problema radica en que el cubrimiento no se hace correctamente, ya que se vulgariza el conocimiento científico para acomodarlo a las audiencias.

El periodismo y la cobertura de temas ambientales se ve tensionado por tres perspectivas: 1 . Se les critica por difundir información minimizada y banalizada de los desastres naturales (Piñuel, 2013); 2. Porque no son precisos en el lenguaje y carecen de fuentes expertas y 3 . Privilegian la generación de controversias alrededor del tema, sin contribuir en la promoción de cambios de comportamientos orientados al cuidado del medio ambiente. Por lo tanto, los discursos mediáticos, como formas de construcción de la realidad, merecen ser identificados y analizados en tanto nutren los mundos de la vida de las audiencias, propiciando actitudes, opiniones, estereotipos, percepciones y representaciones producto de los contextos y los intercambios simbólicos y de sentidos entre quienes lo producen.

El presente artículo ${ }^{4}$, describe las representaciones construidas por los diarios La Opinión y El Tiempo, entre el 2010 -año del hecho- y el 2011, sobre las causas de la destrucción la cabecera municipal de Gramalote, a partir de cuatro categorías emergentes: natural, socio-cultural, gubernamental y religiosa y creencias. De estas surgieron cuatro representaciones: la persona ama/esclava de la naturaleza; un pueblo sin raíces; ausencia de liderazgos; causas místicas y proféticas, siendo estas últimas las de mayores registros en los medios de comunicación de referencia y 
las que orientan la discusión en torno a la valoración de estas narrativas como estrategia de gestión del riesgo y la comprensión de los desastres.

Metodológicamente, la investigación que dio origen a este artículo, se ubicó en el enfoque histórico-hermenéutico porque buscó "construir sentido a partir de la comprensión histórica del mundo simbólico" (Cifuentes, 2011, p. 30); para lograrlo, se recolectaron las notas periodísticas de ambos medios y se segmentaron según su género y estructura; posteriormente, a través de un diseño emergente con codificación abierta, se identificaron y organizaron las familias categoriales conformadas por códigos con características similares.

Finalmente, si bien este análisis no se enmarca en la antropología de los desastres y las catástrofes, sí tiene implicaciones para la investigación en esa línea, por cuanto contribuye a comprender, desde un dispositivo cultural como lo es la prensa escrita, las maneras en qué las personas desde sus narrativas, y los medios de comunicación, al replicarlos, otorgan sentido a las ideas sobre la destrucción y el fin del mundo. En este orden, la desaparición y posterior reconstrucción del casco urbano de Gramalote requieren ser abordadas desde la complejidad de su historia cultural, puesto que "los paisajes del desastre encarnan historias socioambientales y se constituyen en una oportunidad para los antropólogos de tejerlas" (Camargo, 2020, p. 83).

\section{El estudio de las representaciones}

El estudio de las representaciones como marco referencial para abordar diversos fenómenos desde las Ciencias Sociales y Humanas, cobró fuerza a partir de los trabajos paradigmáticos de Abric (1976), Jodelet (1986), Banchs (1986), quienes retomaron los conceptos de Moscovici (1961), desarrollando cuerpos teóricos para la psicología social alrededor del concepto de representación social (acuñado desde la sociología de Durkheim); Chatier (2002) hizo lo propio para la Historia Social y Hall (1997) para los Estudios Culturales.

A su vez, los estudiosos latinoamericanos han adelantado sus propias apuestas investigativas, lo que supone la configuración de una identidad local en la utilización de la teoría, hallándose dos vertientes: "el interés de los investigadores criollos por develar nuestras representaciones para entender el 'ontos' suramericano; y la creatividad como un elemento alimentador de nuevas metodologías y nuevas técnicas de aproximación 
e intervención en las comunidades" (Urbina y Ovalles, 2018, p. 512). Dado carácter transversal, el concepto de representación social se integra con disciplinas diferentes a la psicología y esto permite la comprensión de realidades que se complejizan y transforman de manera constante (Jodelet, 2000).

Para Jodelet (1986), el concepto de representación social describe una forma de conocimiento específico basado en el sentido común, y sus contenidos se manifiestan en la realización de procesos generativos y funcionales signados socialmente.

[...] son modalidades de pensamiento práctico orientadas hacia la comunicación, la comprensión y el dominio del ambiente social, material e ideal. Presentan características específicas en el plano de la organización de los contenidos de las operaciones mentales y de la lógica. El marcaje social de los contenidos o de los procesos debe referirse a las condiciones en las cuales emergen las representaciones, a las comunicaciones en las cuales ellas circulan, a las funciones que ellas sirven en la interacción con el mundo y con los otros. (p. 474)

Moscovici (1961), afirma que toda representación debe ser comprendida y explicada a partir de aquella o aquellas que le dieron origen. En el modelo de Moscovici, el ser humano no es re-productor de las informaciones que recibe y selecciona, sino que es productor de información y significados, por lo tanto, no existe una brecha entre sujeto (mundo interior) y objeto (mundo exterior).

Por su parte, Chatier (2002) centra su discusión sobre las representaciones, en la historia y la escritura donde el mundo del texto y el mundo del lector terminan creando un sentido. En este orden, dicha creación depende de varios contrastes que se dan en relación con el lector, pues es diferente el sentido de un 'letrado virtuoso', al de una persona no tan hábil para la lectura. Variables como las costumbres lectoras, el uso de los libros, las formas de leer y los procedimientos de interpretación hacen que varíen estos sentidos. Para Chatier (2002), las representaciones (colectivas) son las que tejen la historia, teniendo en cuenta que la sociedad es la protagonista de todos los hechos y también los consumidores de las consecuencias. Dado que las características de cada sociedad son distintas y se clasifican, ya sea por sus costumbres, su cultura o su historia, de allí nacen signos que son interpretados por la sociedad como representaciones del proceso histórico. 
A su vez, Hall (1997) refiere que las representaciones son la producción de un sentido mediante el lenguaje que se conforma de conceptos, éstos son los mismos que las personas, con base en su cultura asumen creando su realidad. Existen los conceptos de cosas que se pueden ver y comprobar a través de los sentidos, como también algunos más abstractos que se constituyen de elementos de la realidad que no son comprobables físicamente, pero que como tal se pueden definir y asimilar en la mente, ejemplo de estos, el amor, el respeto, los valores en general, las costumbres, entre otros. Las representaciones se pueden generar en una comunidad, localidad o grupo de personas que con el intercambio de signos, lenguaje, sonidos, gestos e imágenes pueden surgir de un hecho real o imaginario. Para Hall (1997) el lenguaje reparte sentido a lugares y personas distintas para reflejar el mundo y su situación; sin el lenguaje adecuado no hay interpretación de signos y, por ende, no hay representación.

El punto de encuentro entre Chatier (2002) y Hall (1997) está en la creación del sentido o el sentido que las personas toman de la realidad que los rodea, en este caso a través de los textos escritos (notas de prensa); para ambos, la cultura constituye una fuente esencial en la constitución de las apropiaciones, es decir, que influye en la creación del sentido.

A su vez Banchs (1984), tras poner en discusión los conceptos de Jodelet (1986) y Moscovici (1961), compone un concepto de representaciones sociales definiéndolas como una forma de conocimiento de sentido común, propio de las sociedades modernas "bombardeadas constantemente de información por los medios de comunicación de masas" (p. 39). Estas, siguen una lógica diferente a la lógica científica, pero no inferior, y encuentran su expresión en el lenguaje cotidiano de cada grupo social; sus contenidos expresan valores, actitudes, creencias y opiniones que son regulados por las normas de cada comunidad.

Es que la representación como sistema contextualizado incide en la significación bajo dos escenarios: el contexto discursivo y el contexto social (Abric, 2001). El primero se rige por las condiciones que origina la producción del discurso de desde donde es formulada o identificada la representación. Puesto que son, en general, las producciones discursivas las que permiten abordar las representaciones, es clave analizar las características de su producción, y entender que dichas representaciones se producen para un auditorio a quien se espera argumentar y convencer "y que la significación de la representación social dependerá por lo menos en parte de las relaciones concretas que se verifican en el tiempo de una interacción" (Mugny y Carugati citado en Abric, 2001, p. 6). En el segundo 
contexto, tiene que ver con lo ideológico y con el lugar que ocupa el individuo en el grupo social, puesto que la representación social está "anclada siempre en significaciones más generales que intervienen en las relaciones simbólicas propias al campo social dado" (Abric, 2001, p. 7).

En esta investigación, los medios de comunicación, en particular las notas de prensa de los diarios La Opinión y El Tiempo, son los contextos discursivos en donde surgen las representaciones. El hecho de que los periódicos analizados sean de carácter local (en Norte de Santander) y nacional (Colombia), respectivamente, permiten también reconocer dos contextos sociales diferentes, en donde es posible que circulen representaciones diferentes. A su vez estas representaciones permiten comprender el mundo de la vida, la historicidad y la fuerza simbólica que las comunidades les otorgan al paisaje y a los fenómenos naturales, asumiendo o no la carga antrópica en la configuración de los desastres. Es claro, de acuerdo con Barrios (2017), que el origen revelador de los desastres depende del lugar desde donde son observados y su posterior problematización como fenómenos destructivos.

Para este estudio, los dos medios de comunicación develaron una forma particular de asumir la desaparición del casco urbano de Gramalote desde la perspectiva de sus habitantes y a través de sus testimonios, siendo las causas místicas y proféticas las más relevantes para explicar el fenómeno ocurrido. Desde la antropología de los desastres y de las catástrofes, las representaciones ofrecidas contribuyen a la configuración de otros sentidos y simbolismo íntimamente ligados a su historia cultural.

\section{Metodología}

Este es un estudio cualitativo, de tipo histórico-hermenéutico, porque identificó los sentidos construidos y el mundo simbólico con base en una comprensión histórica y de análisis documental en el que se identificaron, describieron y analizaron las representaciones que surgieron de las publicaciones de los diarios La Opinión (local) y El Tiempo (nacional), durante un año: 17 de diciembre de 2010, día que se destruyó el casco urbano de Gramalote, hasta un año después de ocurrido el hecho, el 17 de diciembre de 2011.

El estudio de los mensajes de los medios de comunicación ha estado concentrado en tres métodos: el análisis del discurso, el análisis de contenido y el análisis semiótico cuando se quiere identificar el tratamiento periodístico, la ideología del medio frente a un tema o el encuadre. Sin embargo, esta investigación apeló a la codificación abierta como método 
para identificar, relacionar y comprender la familiaridad de los códigos expuestos en las notas de prensa (Bernal et al., 2016). Esto debido a tener como objetivo la identificación de las representaciones -entendidas como una forma de conocimiento de sentido común propio de las sociedades modernas, con una lógica que encuentran su expresión en el lenguaje cotidiano de cada grupo social (Banchs, 1896), y teniendo en cuenta que los medios masivos de comunicación hacen uso de ese lenguaje para dar sentido a las realidades.

El corpus documental está constituido por 48 piezas (43 de La Opinión y 5 de El Tiempo) y, para su selección, se definieron cuatro criterios:

1. Notas publicadas en los dos periódicos seleccionados (La Opinión y El Tiempo). Se tomaron como fuentes principales para la recolección de información los diarios La Opinión y El Tiempo, ya que se quiso analizar las representaciones desde una perspectiva local y nacional.

2. Noticias publicadas en El Tiempo establecido (17/12/2010 17/12/2011). El objetivo era conocer no sólo los elementos periodísticos que se publicaron en el auge de la situación, sino también las distintas representaciones creadas hasta un año después del suceso a partir de las diferentes publicaciones periodísticas.

3. Notas periodísticas que nombraran las diferentes causas medioambientales que provocaron la destrucción del casco urbano del municipio.

4. Que en las notas se evidenciaran las opiniones que surgieron de los diferentes grupos sociales y entidades que se vieron afectados por la destrucción del casco urbano.

Es importante aclarar que no se tomaron en cuenta los elementos noticiosos que pertenecían a las secciones: editorial u opinión, y que el diario El Tiempo publicó durante el periodo seleccionado más notas relacionadas con la destrucción del casco urbano de Gramalote. Sin embargo, estas no cumplían los cuatro criterios de selección y fueron descartadas para esta investigación.

El total de las notas publicadas por cada uno de los diarios y por mes se registra en la Tabla 1. 
Tabla 1. Total de notas publicadas por diario y por mes

\begin{tabular}{lccc}
\hline Mes-2010 & La Opinión & El Tiempo & Total \\
\hline Diciembre & 15 & 3 & 18 \\
\hline Meses-2011 & & & \\
\hline Enero & 13 & 1 & 3 \\
\hline Febrero & 2 & - & 3 \\
\hline Marzo & 3 & - & 0 \\
\hline Abril & - & - & 1 \\
\hline Mayo & 1 & - & 1 \\
\hline Junio & 1 & - & 0 \\
\hline Julio & - & - & 0 \\
\hline Agosto & - & - & 0 \\
\hline Septiembre & - & - & 0 \\
\hline Octubre & - & 1 & 2 \\
\hline Noviembre & 73 & - & 7 \\
\hline Diciembre & 7 & 5 & 2 \\
\hline Total & & & 2 \\
\hline
\end{tabular}

Fuente: Bernal et al. (2016).

\section{Procedimientos para la recolección y análisis de la información}

Primera fase: se efectúo la descripción de los textos noticiosos seleccionados a través de la Ficha Técnica 1. Recolección y Caracterización del Corpus Total, ésta se utilizó para ordenar las notas periodísticas que se recopilaron de las publicaciones hechas por las fuentes principales de la investigación (Tabla 2). En la primera casilla se dio a cada nota periodística un número para ordenarlas; en la segunda se identificó la fecha en que fueron publicadas, teniendo en cuenta el criterio de temporalidad de la investigación; la tercera casilla relacionó el nombre de la sección donde fue publicada la nota periodística para resaltar la importancia y la temática que les dio cada diario a dichas noticias; en la cuarta casilla se documentó el titular dado por el medio impreso a cada noticia, entendiendo éste como el principal elemento de una nota, ya que representa de manera reducida el contenido; en la quinta, si la nota tenía lead (párrafo introductorio que responde a las cinco preguntas orientadoras del periodismo: qué, dónde, cuándo, quiénes y por qué). Cada noticia tiene, por lo general, fuentes de información, testimonios de autores involucrados en los sucesos, que complementan lo investigado por el periodista, estas fuentes fueron identificadas en la casilla seis. En la séptima casilla se determinó el género 
periodístico al que pertenecía la publicación, fuera noticia, crónica, reportaje o informe.

Tabla 2. Ficha técnica 1. Recolección y Caracterización del Corpus Total

\begin{tabular}{cll}
\hline n. ${ }^{\circ}$ de casilla & \multicolumn{2}{c}{ FICHA DE RECOLECCIÓN DE DATOS DEL DIARIO LA OPINIÓN } \\
\hline 1 & Número de Registro & 43 \\
\hline 2 & Fecha & 22 de diciembre 2011 \\
\hline 3 & Ubicación de Sección & Informe 6B-7B \\
\hline 4 & Título & La lomita, o la tierra que se resiste a desaparecer. \\
\hline 5 & Lead & No tiene. \\
\hline 6 & Fuente(s) & $\begin{array}{l}\text { AyozeO'Shanahan, Español, María Fernanda Céspedes, } \\
\text { documentalistas; Óscar Sánchez, habitante de Gramalote, } \\
\text { Carlos Julio Ramírez, Líder comunal; Marina, Habitante de } \\
\text { Gramalote, Jaime Barrera, carnicero de Gramalote, Karen, } \\
\text { Odontóloga de Gramalote; Gustavo Enrique Suárez, maestro } \\
\text { de ceremonia; Emín Mora, Párroco. }\end{array}$ \\
\hline 7 & Género Periodístico & Informe \\
\hline
\end{tabular}

Fuente: Bernal et al. (2016).

Segunda fase: se identificaron y construyeron familias de códigos que permitieron la conformación de categorías, de las cuales se surgieron las representaciones. Una vez recuperadas las notas se prensa se realizó un proceso de codificación abierta, entendido como el proceso de abordar un texto, con el objetivo de "desnudar conceptos, ideas y sentidos" (San Martín, 2014, p. 3). En concordancia con Strauss y Corbin (2002), este trabajo es inductivo, pues no se tienen en cuenta teorías ni se aplican conceptos ni leyes o dimensiones al texto que se está codificando. Para el caso particular, el procedimiento consistió en separar por segmentos con sentido los diferentes códigos, a estos se les llamó de dos formas: códigos in vivo, si la frase era seleccionada del documento o citado de manera textual, es decir, con las palabras exactas de lo escrito en la noticia; y constructos sociológicos, cuando esta frase era una elaboración hecha en la investigación a partir del contenido de la nota de prensa, tal como se presenta en la Tabla 3. 
Tabla 3. Ficha técnica 2. Codificación abierta, periódico La Opinión

\begin{tabular}{ll}
\hline & \multicolumn{2}{c}{ CODIFICACIÓN ABIERTA - LA OPINIÓN } \\
\hline LO-26 & 17 de enero de 2011 \\
\hline Código in vivo & Construcción sociológica \\
\hline * Tragedia anunciada. & * Abertura en la tierra. \\
* Hecatombe de Gramalote. & * Inestabilidad del terreno. \\
* El deslizamiento que se está presentando amenaza & * Presagio. \\
con convertirse en una avalancha que arrasaría & *Cartas de advertencia ante el inminente \\
parte de Jácome y pasaría por el pueblo. & peligro. \\
* La tierra venía abriéndose desde hacía tres años. & \\
* Deslizamiento de tierra. & \\
* Constantes Derrumbes. & \\
* Situación invernal. & \\
* Agrietamiento del terreno. & \\
* La quebrada se desbordó. & \\
* La tierra se revolcó. &
\end{tabular}

Fuente: Bernal et al. (2016).

Tercera fase: consistió en la organización en familias de los segmentos destacados anteriormente, esto quiere decir, la agrupación de dichas frases que se relacionaban entre sí; se les dio a las familias un nombre, estableciéndose la relación entre los diferentes códigos, como se evidencia en la Figura 1.

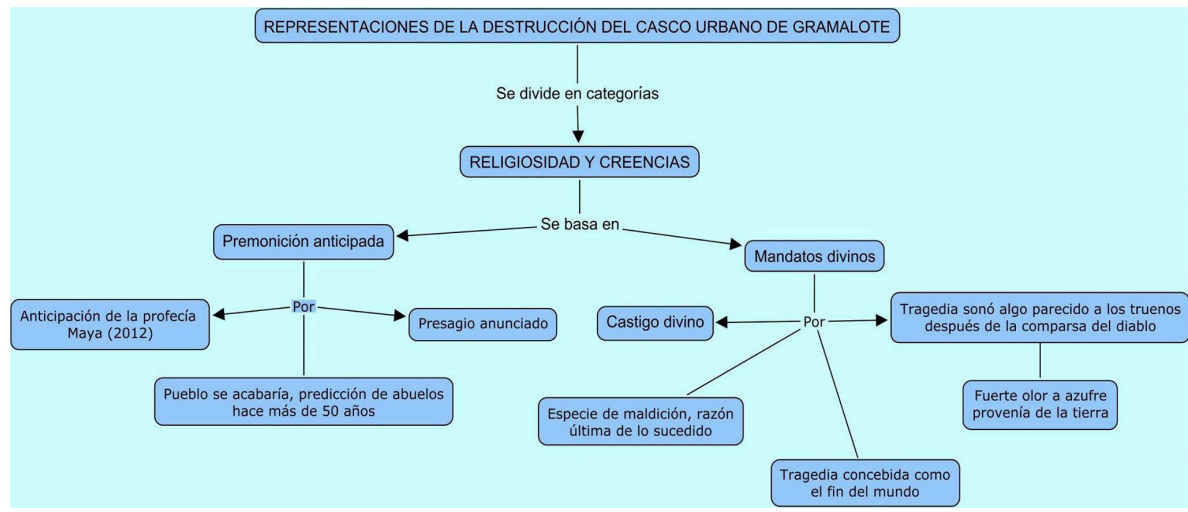

Figura 1. Mapa Conceptual de la Categoría Religiosidad y Creencias, periódico La Opinión.

Fuente: Bernal et al. (2016).

Cuarta fase: a partir de estas familias de códigos se nominaron cuatro representaciones, una por cada categoría que emergió del análisis de las notas periodísticas, así:

» Familia categorial Naturaleza, se le asignó la representación: la persona ama/esclava de la naturaleza. 


\section{Hallazgos y discusión}

Del análisis de las 48 notas, surgieron cuatro familias categoriales en La Opinión: ambiental, sociocultural, gubernamental, religiosidad y creencias; las notas analizadas de El Tiempo arrojaron las mismas categorías, exceptuando la gubernamental.

De la categoría ambiental, se destacaron causas como: la falla geológica, la ola invernal, movimientos telúricos, tala de bosques y deslizamientos. En la categoría sociocultural, se encontró que los diarios representaron la destrucción como un hecho catastrófico que no sólo involucró la pérdida de su infraestructura, sino que también género pérdidas del tejido social, la historia y las costumbres que identifican a la comunidad. La tercera, gubernamental, se caracterizó por resaltar el papel que los entes de poder tuvieron frente al desastre, desde el hecho de no prestar atención al problema de inestabilidad que había en los suelos, hasta la incapacidad de realizar obras para la mitigación del riesgo por la falla geológica donde estaba asentado el casco urbano, pese a que se había remitido cartas de advertencia ante el inminente peligro. La cuarta, religiosidad y creencias, se evidenció que los habitantes contaban visiones de este corte muy arraigadas a su cultura, por lo que se atribuyó el hecho a un castigo divino, una profecía hecha realidad o el apocalipsis.

Ambos diarios se enfocaron en un periodismo netamente informativo, buscando la espectacularización del hecho, corroborando lo señalado por Piñuel (2013), por lo tanto, existió una comunicación del desastre y no del riesgo, hecho que critican Castillo y López (2019), puesto que es evidente la intencionalidad de los medios de mostrar los desastres "como un tema más en el amplio mercado mediático referido a los 'males de la naturaleza"' (p. 21), sin comprender a los aceleradores antrópicos. 


\section{Representaciones en la categoría ambiental: la persona ama/esclava de la naturaleza}

Los principales códigos empleados en las notas de La Opinión y El Tiempo fueron: falla geológica; invernal y movimientos telúricos. Estos, en conjunto, conformaron una categoría que reveló las causas atribuidas al medioambiente: la persona ama/esclava de la naturaleza. En esta se evidencia que la intervención humana, por acción u omisión y las consecuencias de desconocer el territorio, propiciaron su destrucción.

El diario local planteó a los lectores que lo ocurrido estuvo propiciado por acciones antrópicas, pues expuso que la inestabilidad del terreno se debió a la tala indiscriminada de bosques y a la falta de control de estas actividades por parte de entidades encargadas de los asuntos ambientales. Según el titular "No dejar perder la vocación agrícola", declara, por la tala indiscriminada de bosques, que ha sido en parte, la causa del problema" (La Opinión, 2010, 26 de diciembre). Así mismo, en el titular "El apocalipsis de Gramalote" declara: "Era de esperarse. Nunca se estudiaron las fallas geológicas que atravesaban el pueblo... el mismo estudio se establecía un fenómeno de inestabilidad geológica..." (La Opinión, 2010, 26 de diciembre). Para El Tiempo la destrucción sucedió como consecuencia natural: una falla geológica y la ola invernal que vivía el país. Un titular del 18 de diciembre del 2010 fue: "Pánico en Gramalote por falla geológica" (El Tiempo).

\section{Representaciones en la categoría sociocultural: un pueblo sin raíces}

La categoría sociocultural está ligada a las prácticas sociales y culturales de la comunidad residente de Gramalote, y en cómo estás resultaron afectadas con la destrucción del casco urbano. El diario local La Opinión, representó la tragedia ocurrida a través de los códigos correlacionados con los sistemas conceptuales y de lenguaje de los habitantes afectados, quienes trasmitieron al medio impreso sus testimonios, y éste a su vez, difundió lo relatado por los protagonistas del hecho: un pueblo sin raíces. Los códigos destacados en esta categoría fueron: tragedia; desaparición del pueblo; pérdida histórica y zona de desastre. Para La Opinión, los habitantes percibieron esa destrucción como el despertar de un monstruo, que hizo llorar y rugir un cerro, sembrando terror y una larga agonía a la vez que el municipio se hundía por su propio peso. Un titular de La Opinión del 18 de diciembre de 2010 expresó "La montaña ruge y Gramalote huye". También se referenció el municipio con un pueblo fantasma que permitió a la soledad y a la nada instaurar su imperio; además, de la pérdida histórica significativa de bienes materiales e inmateriales. 
El titular "Destrucción eminente" declara "Caos total. Desesperación, lágrimas e impotencia, recorren las calles agrietadas de Gramalote. Ya no hay nada qué hacer, la desaparición del pueblo es inminente" (La Opinión, 2010, 19 de diciembre).

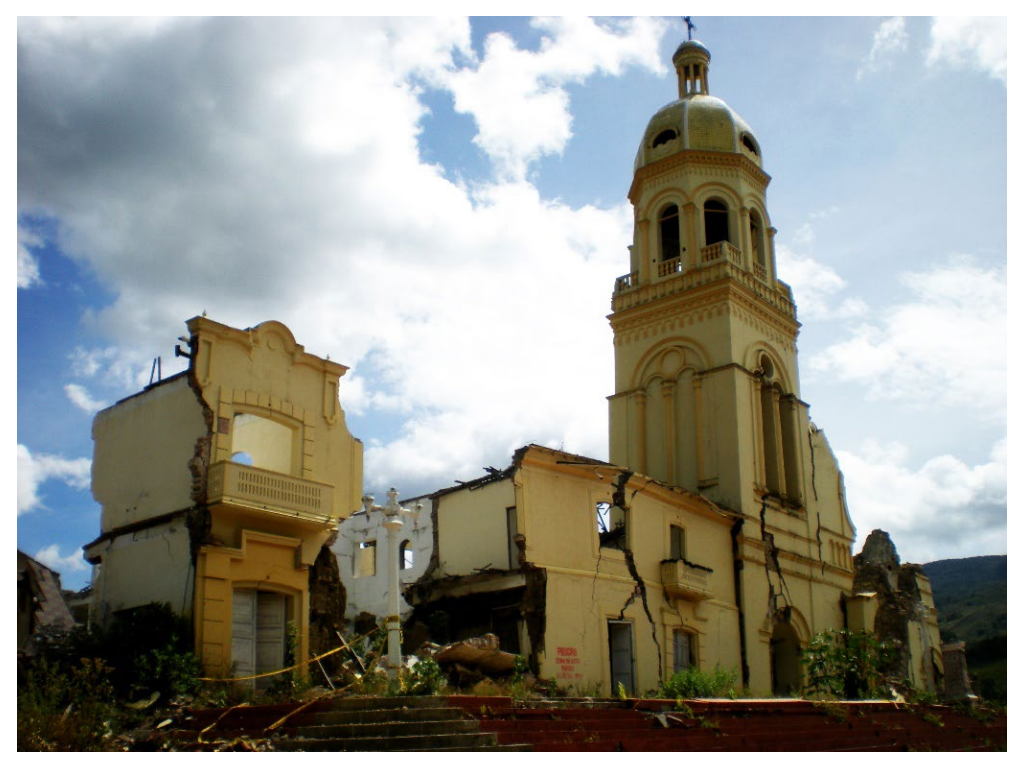

Figura 2. Templo de Gramalote.

Fuente: Diana Feo Ardila (2013).

En este aspecto, El Tiempo, en su titular "Seis mil personas dieron último adiós a Gramalote", presentó la destrucción del territorio como un hecho fatal, el cual fue comparado con los diferentes sucesos catastróficos ambientales que ocurrieron durante la temporada invernal que enfrentaba el país. Asimismo, se referenció que después de la tragedia, Gramalote se convirtió en un pueblo fantasma, en el que sólo se podía apreciar ruinas (El Tiempo, 2010, 20 de diciembre). 


\section{Representaciones en la categoría gubernamental: ausencia de liderazgo}

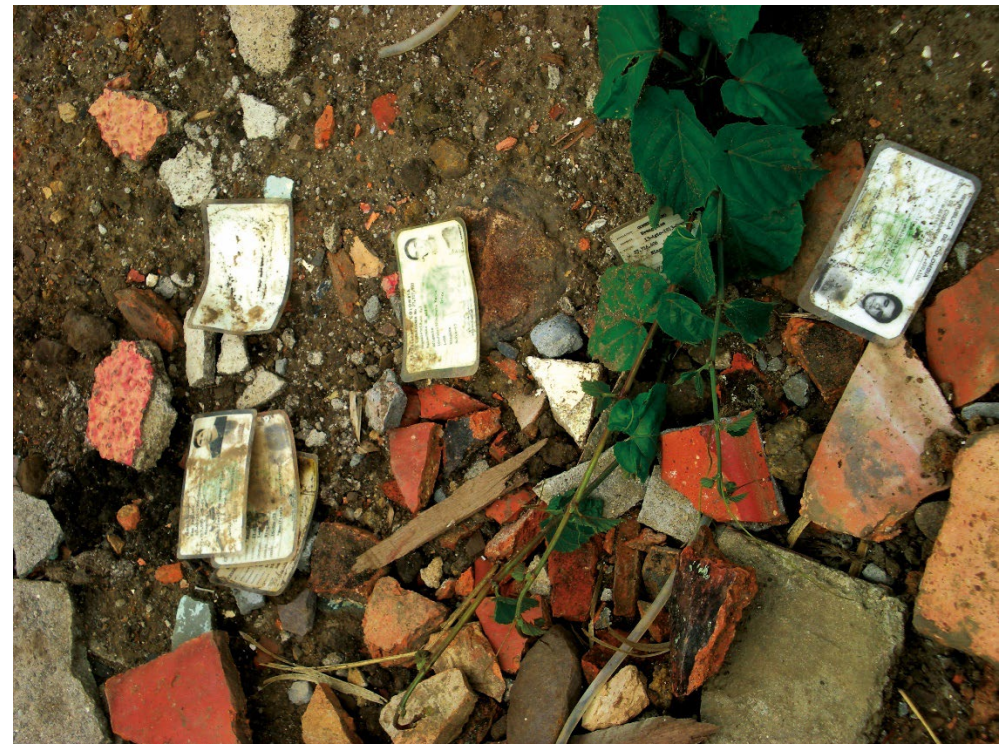

Figura 3. Ciudadanía 'vencida'.

Fuente: Diana Feo Ardila (2013).

La Opinión presentó al ente gubernamental como descuidado y carente de interés por la estructura del casco urbano de Gramalote. Las notas resaltaron que no se prestó atención a los estudios realizados en el terreno, los cuales evidenciaban la necesidad de un plan de prevención y mitigación de riesgo que pudo haber evitado que el suceso llegara a afectar de tal manera a la población. El medio fue claro en explicar la inestabilidad en los suelos, hecho que fue evidenciado por diferentes habitantes del pueblo y veredas aledañas, quienes, en su preocupación por hacer un llamado de atención al Gobierno local, enviaron una gran cantidad de cartas donde se describía la situación y el estado que presentaba el terreno ante la temporada invernal y a las fallas geológicas presentes; estas cartas sólo obtuvieron vagas respuestas por parte del mandatario local de la época, explicando que la situación ya se había comunicado a Bogotá y "¿Qué podemos hacer contra la naturaleza?" otorgándole así poder omnipotente. La Opinión en su titular "La tierra venía abriéndose desde hacía tres años", declara "Reconoció que en su despacho reposaban muchas cartas, entre esas, las de la profesora Omaira Ibarra... Ellos me dijeron: profesora, eso está a nivel Bogotá, eso se ha informado..." (La Opinión, 2011, 17 de enero). 
En El Tiempo ${ }^{6}$ no surgieron representaciones basadas en la categoría gubernamental, ya que en las notas no se hallaron códigos que aludieran a las versiones de los organismos del Estado frente a la destrucción del casco urbano de Gramalote. De esta manera, en el corpus recogido y analizado, el medio nacional desvincula a los gobiernos de toda responsabilidad frente al hecho, separa al Estado de su función de velar por el adecuado uso del suelo, propio del ordenamiento territorial que está en sus manos. En este sentido, se comparte lo propuesto por Alcaraz (2012), cuando señala que los actores y las instituciones gubernamentales tienen la responsabilidad de atender las problemáticas ambientales, de visualizarlas y ponerlas en discusión pública. A su vez, Lampis et al. (2020), proponen trabajar en una agenda participativa de adaptación que incluya a la sociedad civil en interacción con la academia y el gobierno, en pos de una perspectiva de aprendizaje social que incremente el diálogo para la construcción de nuevo paradigma de transformación en la forma como se planifican y gobiernan las ciudades y los recursos naturales.

\section{Representaciones en la categoría religiosidad y creencias: místicas y proféticas}

En las notas analizadas, La Opinión relacionó la destrucción del casco urbano con las causas de carácter religioso y creencias que estaban arraigadas en la población. Se identificaron las representaciones místicas y las proféticas. Las causas místicas explican que el desastre ocurrido estuvo influenciado por mandatos divinos, eventos espirituales relacionados con el dios cristiano y la Virgen María, creencias vinculadas a la religiosidad de su población. Tal como se evidencia en este titular "Huyan, huyan que el pueblo se va a hundir" declara "Una semana antes se había soñado con la Virgen María que le advertía: ore mucho para que ninguno de mis hijos perezca" (La Opinión, 2011, 16 de enero). Las referencias a una maldición que recaía sobre Gramalote, se contemplaron como la razón última de la destrucción del pueblo, lo que despertó la curiosidad de un equipo de documentalistas extranjeros, quienes decidieron hurgar en ese pasado y grabar 'La maldición, el milagro y el burro', una producción audiovisual que resalta a un pueblo destruido y olvidado tras haber pasado un año de lo ocurrido.

En cuanto a la representación profética, se representó el suceso como el inicio anticipado de la destrucción del mundo, una profecía hecha por

Es importante recalcar que el diario nacional sí publicó noticias relacionadas a las menciones que hizo el Gobierno sobre la destrucción del casco urbano de Gramalote, pero éstas no contaban con todos los atributos establecidos para el corpus de esta investigación. 
la cultura maya para el año 2012. El presagio es una constante en las notas publicadas como se evidencia en este titular y nota "Gramalote ¿claudicó de manera natural o sobrenatural?... "El pueblo se acabaría. Predicción de los abuelos hace 50 años". (La Opinión, 2011, 2 de enero). Acá se ponen en disputa dos percepciones del mundo antagónicas e inseparables: la naturaleza como ente autónomo y lo divino, lo mágico, lo que está por encima. Ambas partes son imposibles de contener, no tienen explicación y actúan siguiendo su propio ritmo y destino. De este modo, la destrucción del casco urbano era irreversible e invariable, con afectaciones antrópicas o sin ellas. Hay entonces una liberación de responsabilidad, pero también un sometimiento a sus leyes sin posibilidad de maniobra, como lo señala Cagüeñas (2013), pues temblores, inundaciones y deslaves recuerdan nuestras propias limitaciones. Sin embargo, "lo inevitable, lo finito y lo irreversible dan forma a la experiencia del desastre, pero al mismo tiempo abren el camino a la reconstrucción de la vida" (p. 224).

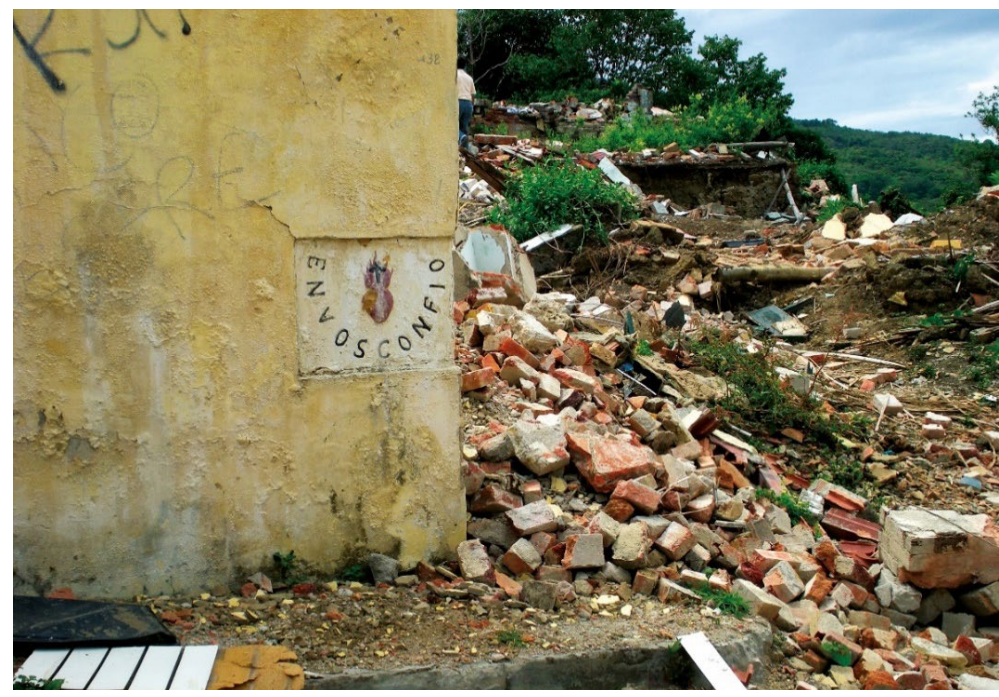

Figura 4. Religiosidad de lo cotidiano.

Fuente: Diana Feo Ardila (2013).

El periódico local, de acuerdo con la versión de sus fuentes, enfocó las causas del hecho una serie de mandatos divinos influenciados por personajes religiosos causantes de castigar a la comunidad; también hicieron alusión a sucesos malignos y comparando el sonido del deslizamiento de la tierra con los truenos que se escuchan "cuando pasa la comparsa del diablo" ('Huyan, huyan que el pueblo se va a hundir', 16 de enero del 2011, La Opinión). Mencionaron, además que, al abrirse, la tierra emanó de ella un fuerte olor a azufre. 
En el Tiempo, las notas estuvieron relacionadas con predicciones y maldiciones, así como las creencias de los pobladores a raíz de un testimonio dado por un habitante del pueblo, quien mencionó que la causa de la tragedia se debió a la maldición que hizo el sacerdote Raymundo Ordóñez Yáñez, este dijo que Gramalote sería destruido y que sobre él nacería un tartagal ${ }^{7}$. El diario nacional evidenció las fuertes raíces religiosas y un gran temor a dios de los habitantes de Gramalote, pues las notas publicadas aludían a que la destrucción del casco urbano estaba relacionada con algo más allá de lo terrenal, anteponiendo predicciones y una gran creencia frente a lo ocurrido como voluntad de dios. En la nota con el titular "No volveré a Gramalote, son muchos los recuerdos" expusieron "El padre al marcharse del pueblo dijo que Gramalote, sería destruido y que sobre él nacería un tartagal, cuenta. Mira al cielo y dice que "la lengua de los padres es bendita"' (El Tiempo, 2010, 26 de diciembre).

Pero estas causas místicas, oscuras o mágicas de la destrucción no son exclusivas de Gramalote y desde la apuesta de Suárez (2009) deberían ser contempladas para comprender tragedias como la de Armero. Aunque Guion et al. (2007) critiquen la ausencia de un acuerdo general sobre el uso y direccionamiento de los medios en la comunicación e información en emergencias, por lo que es posible hallar discursos y narrativas no alineadas con la ciencia o la explicación experta de los acontecimientos, Suárez (2009) sugiere que hay más inteligencia en estas causas "que la que con desdén les reconoce la ciencia colombiana. Y no he agotado, a lo sumo vislumbro, la complejidad de la intrincada teoría del mundo que soporta todas estas informaciones" (p. 441). Lo preocupante, señala Suárez (2009), es que este desdeño mantiene a científicos y expertos (incluso a la prensa) tremendamente lejos de las personas y los hechos que se esperan comprender. En este punto concuerda con la teoría de las representaciones sociales propuesta por Abric (2001), para quien el estudio de lo que podría considerarse el pensamiento 'ingenuo' o del 'sentido común', es fundamental en la identificación de la visión del mundo, que tanto los individuos como los grupos asumen y se sirven para actuar o tomar posiciones. Por lo tanto, identificar las representaciones es indispensable para entender la dinámica de tales interacciones sociales y develar qué determina ciertas prácticas sociales.

En el caso particular de este estudio, se halló que los diarios resaltaron las versiones de una población devota a su fe católica y a su postura conservadora, los cuales mencionaban que la destrucción del casco

Zona verde constituida por tártagos, arbustos que prevalecen en suelos del bosque tropical seco, y que tienen sus tallos y hojas con espinas. 
urbano hacía parte de una escena del apocalipsis, tomando sus testimonios de manera directa y dejando las versiones en las propias voces de los damnificados sin profundizar sobre las mismas. Así, de darse esta compresión, podría hacerse una gestión socionatural del riesgo que propiciara el reconocimiento de los factores antrópicos que agudizan los fenómenos, pero también de las acciones que las sociedades afectadas asumen para reorganizar su paisaje, habitarlo en nuevas condiciones y reacomodar su reciente historia cultural con una nueva percepción del mundo a pesar de la crisis.

\section{Conclusiones}

Del análisis de las 48 notas periodísticas publicadas entre el 17 de diciembre del 2010 al 17 de diciembre del 2011 en los periódicos La Opinión (local) y El Tiempo (Nacional) sobre las causas de la destrucción del casco urbano de Gramalote, surgieron tres familias categoriales similares en ambos medios: ambiental, sociocultural y religiosidad y creencias; y la gubernamental solo en el diario local. Éstas permitieron la configuración a su vez, de cuatro representaciones así: la persona ama/esclava de la naturaleza; un pueblo sin raíces; ausencia de liderazgos; y causas místicas y proféticas.

Al analizar estos medios escritos se evidenció cómo elementos socioculturales o religiosos toman protagonismo en las publicaciones, minimizando temáticas como la gestión de riesgo y de desastres. No obstante, la prensa escrita, y en general, los medios de comunicación develan una oportunidad para la antropología del desastre en Colombia, pues desde sus narrativas permiten un acercamiento al hecho y a las cargas simbólicas que este gestionó en los involucrados. Un trabajo posterior implicaría profundizar en campo la comprensión de estas representaciones. Se constituye así en una oportunidad para revalorizar las representaciones sociales que construyen los habitantes de las causas de los desastres para identificar rutas y re elaborar narrativas y prácticas de gestión del riesgo, que estén más acordes con los simbolismos que les otorgan las comunidades a su territorio y su relación y comprensión del paisaje.

A pesar de que temas como la crisis económica mundial, el terrorismo, los procesos de paz y la vida de famosos artistas y deportistas, son los que marcan la agenda de los medios, la inestabilidad del medio ambiente, los cambios climáticos, los fenómenos naturales, entre otros, serán a futuro sucesos más noticiosos y con mayor auge debido a la cantidad de personas que afectan, por lo tanto, es imperativo que los 
medios masivos de comunicación integren diversas visiones del desastre de modo que se avance hacia una comprensión del riesgo socionatural, donde se profundizan las sinuosas relaciones que se tejen entre el medio ambiente, la política, la cultura y el poder.

Adicionalmente, es importante subrayar las implicaciones que en la concepción del fin del mundo ofrecen las representaciones mediáticas analizadas en este trabajo, pues están arraigadas en el destino, en lo indecible (el misterio, de lo que nadie quiere hablar), pero ineludible (porque la suerte estaba echada para Gramalote tras la maldición de un sacerdote). Así, los medios masivos hacen evidentes los entramados de sentidos que envuelven a las comunidades, permitiendo su estudio y comprensión en las fronteras de lo mágico y lo sagrado. Para Gramalote, el fin del mundo pasó por la desaparición del casco urbano, pero permitió la recuperación de memorias y profecías que hacían parte de su universo simbólico arraigado en la religión católica, en la culpa y el castigo.

\section{Referencias bibliográficas}

Abric, J. C. (1976). Jeux, conflits et représentations sociales (Tesis de doctorado). Universidad Aix, Provence.

Abric, J. (2001). Las RS: aspectos teóricos. En J. C. Abric (ed.), Prácticas sociales y representaciones (pp. 11-32). Ediciones Coyoacán.

Alcaraz, L. G. (2012). Medio ambiente y agenda mediática. Oportunidades y barreras para la cobertura periodística de cuestiones ambientales en la prensa local. Revista Oficios Terrestres, 1(28), 1-27. https://perio.unlp.edu.ar/ojs/index.php/oficiosterrestres/ article/view/1612/1424

Andrade, P., Flores., R. y Mendoza., F. (2018). Fenómenos naturales y desastres humanos en la prensa impresa de México. De la información a la representación social. Global Media Journal México, 14(27), 124-148. http://www.redalyc.org/articulo.oa?id=68753898007

Banchs, M. A. (1984). Las representaciones sociales: sugerencias sobre una alternativa teórica y un rol posible para los psicólogos sociales en Latinoamérica. Anthropos: Boletín de información y documentación, (44), 15-20.

Banchs, M. A. (1986). Concepto de "representaciones sociales" Análisis comparativo. Revista Costarricense de Piscología, (8-9), 27-40. http://rcps-cr.org/wp-content/uploads/ 2016/05/1986.pdf

Barrios, R. E. (2017). What Does Catastrophe Reveal for Whom? The Anthropology of Crises and Disasters at the Onset of the Anthropocene. Annual Review of Anthropology, 46, 151-166. https://doi.org/10.1146/annurev-anthro-102116-041635

Bernal, K., Amaya, D. y Sánchez, A. (2016). Representaciones de la destrucción del casco urbano de Gramalote en La Opinión y El Tiempo 2010-2011 (Tesis de pregrado). Universidad Francisco de Paula Santander, Cúcuta. 
Cagüeñas, D. (2013). Mundos en la estela del desastre, esbozos para una historia de la finitud. En M.R. Acosta y C. Manrique (eds.), A la sombra de lo político, violencias institucionales $y$ transformaciones de lo común (pp. 223-240). Universidad de Los Andes.

Camargo, A. (2020). Thinking through disaster. Ethnographres and disastrous and landscapes in Colombian. En V. García-Acosta (ed.), The antrophology of disasters in Latin American. State of the art (pp. 82-101). Routlegde.

Castillo, O. A. y López, N. (2019). El desastre es el mensaje. Un análisis de la prensa escrita y Facebook, sobre las inundaciones en Tultitlán, México. Revista Encuentros, 17(1), 11-23. https://dialnet.unirioja.es/servlet/articulo?codigo=6860600

Carabaza, J. (2007). El papel de la prensa en la construcción de las representaciones sobre la problemática ambiental en los habitantes de Saltillo, Coahuila. Convergencia. Revista de Ciencias Sociales, 14(43), 39-71. http://www.redalyc.org/articulo.oa?id=10504303

Chartier, R. (2002). El mundo como representación: estudios sobre historia cultural. Editorial Gedisa.

Cifuentes, R. M. (2011). Diseño de proyectos de investigación cualitativa. Noveduc Libros. http://files.coordinacion-de-investigaciones.webnode.com.co/20000002147c0549bf3/Enfoque\%20de\%20investigación.pdf

El Tiempo. (18 de diciembre del 2010). Pánico en Gramalote por falla geológica. https://www. eltiempo.com/archivo/documento/MAM-4312439

El Tiempo. (20 de diciembre del 2010). Seis mil personas dieron último adiós a Gramalote. https://www.eltiempo.com/archivo/documento/MAM-4315480

El Tiempo. (26 de diciembre del 2010). No volveré a Gramalote, son muchos los recuerdos. https://www.eltiempo.com/archivo/documento/MAM-4322905

Guion, D., Scammon, D. L. y Borders, A. L. (2007). Weathering the storm: A social marketing perspective on disaster preparedness and response with lessons from hurricane Katrina. Journal of Public Policy \& Marketing, 26(1), 20-32. http://dx.doi.org/10.1509/ jppm.26.1.20

Hall, S. (1997). El trabajo de la Representación. En S. Hall, El trabajo de la Representación (pp. 13-74). Sage Publications.

Jodelet, D. (1986). La representación social: fenómenos, conceptos y teoría. En S. Moscovici (ed.), Psicología Social II (pp. 469-494). Paidós.

Jodelet, D. (2000). Representaciones sociales: Contribución a un saber sociocultural sin fronteras. En D. Jodelet y A. Guerrero (eds.), Develando la cultura. Estudios en representaciones sociales (pp. 7-30). UNAM.

Lampis, A., Campello, P., Jacobi, P. y Leonel, A. (2020). A produção de riscos e desastres na América Latina em um contexto de emergência climática. O Social em Questão, (48), 75-96. http://osocialemquestao.ser.puc-rio.br/media/OSQ_48_Art_3.pdf

La Opinión. (18 de diciembre de 2010). La montaña ruge y Gramalote huye. Regional 2A.

La Opinión. (19 de diciembre de 2010). Destrucción eminente. Gramalote 3A.

La Opinión. (26 de diciembre de 2010). No dejar perder la vocación agrícola. Gramalote 2A.

La Opinión. (26 de diciembre de 2010). El apocalipsis de Gramalote. Panorama 11B.

La Opinión (16 de enero de 2011). 'Huyan, huyan que el pueblo se va a hundir'. Gramalote 5B. 
La Opinión. (17 de enero de 2011). La tierra venía abriéndose desde hacía tres años. Portada 1A-Gramalote 1C.

La Opinión. (2 de enero de 2011). Gramalote ¿claudicó de manera natural o sobrenatural? Gramalote 4B.

Llasat-Botija, M., Llasat, M.C. y Cortés, M. (2016). De la prensa a las Apps. Un recorrido por la comunicación de los riesgos naturales en la prensa escrita y el papel de las nuevas tecnologías. En Actas del I Congreso Internacional Comunicación y Pensamiento. Comunicracia y Desarrollo Social (pp. 785-807). Universidad de Sevilla. http://hdl. handle.net/11441/50750

Lörcher, I. y Neverla, I. (2015). The Dynamics of Issue Attention in Online Communication on Climate Change. Media and Communication, 3(1), 17-33. https://www.cogitatiopress. $\mathrm{com} /$ mediaandcommunication/article/view/253

Moscovici, S. (1961). El psicoanálisis, su imagen y su público. Huemul.

Ortiz, A. M. (2015). La observación de las representaciones mediáticas del medio ambiente en la prensa. El caso de "La Crónica de Baja California", México. Mediaciones Sociales, (14), 59-79. https://doi.org/10.5209/rev_MESO.2015.n14.51559

Piñuel, J. L. (2013). Editorial. Anuario Electrónico de Estudios en Comunicación Social "Disertaciones", 6(1). http://erevistas.saber.ula.ve/index.php/Disertaciones/issue/ view/309

Reis, C., Durieux, F. y Darolt, E. (2013). La comunicación del ayuntamiento de Blumenau (Brasil) durante el desastre natural de noviembre de 2008: el reto de la planificación a largo plazo. Anuario Electrónico de Estudios en Comunicación Social "Disertaciones", 6(1), 86-105. http://erevistas.saber.ula.ve/index.php/Disertaciones/

Schäfer, M. y O'Neill, S. (2017). Frame Analysis in Climate Change Communication. En Oxford Encyclopedia of Climate Change Communication. En S. Ho, E. Markowitz, S. O’Neill, M. Nisbet, J. Thaker, M. S. Schäfer (eds). http://dx.doi.org/10.1093/ acrefore/9780190228620.001.0001/acrefore-9780190228620-e-487

San Martín, D. (2014). Teoría fundamentada y Atlas.ti: recursos metodológicos para la investigación educativa. Revista Electrónica de Investigación Educativa, 16(1), 104-122. http://redie.uabc.mx/redie/article/view/727/891

Strauss, A. y Corbin, J. (2002) Bases de la investigación cualitativa. Técnicas y procedimientos para desarrollar la teoría fundamentada. Universidad de Antioquia.

Suárez, L. (2009). Lluvia de flores, cosecha de huesos. Guacas, brujería e intercambio con los muertos en la tragedia de Armero. Maguaré, (23), 371-416. https://revistas.unal.edu. co/index.php/maguare/article/view/15058

Tagle, F. (2017). Framing y desastres naturales: encuadre a la prensa escrita chilena. Perspectivas de la Comunicación, 10(1), 137-156. http://revistas.ufro.cl/ojs/index. $\mathrm{php} /$ perspectivas/article/view/690/695

Urbina, J. E. y Ovalles, G. A. (2018). Teoría de las representaciones sociales. Una aproximación al estado del arte en América Latina. Psicogente, 21(40), 495-544. https://doi. org/10.17081/psico.21.40.3088 